\title{
Consensus, compromise, justice and legitimacy
}

\author{
Enzo Rossi ${ }^{1}$
}

\begin{abstract}
Could the notion of compromise help us overcoming - or at least negotiating the frequent tension, in normative political theory, between the realistic desideratum of peaceful coexistence and the idealistic desideratum of justice? That is to say, an analysis of compromise may help us moving beyond the contrast between two widespread contrasting attitudes in contemporary political philosophy: 'fiat iustitia, pereat mundus' on the one side, 'salus populi suprema lex' on the other side. More specifically, compromise may provide the backbone of a conception of legitimacy that mediates between idealistic (or moralistic) and realistic (or pragmatic) desiderata of political theory, i.e. between the aspiration to peace and the aspiration to justice. In other words, this paper considers whether an account of compromise could feature in a viable realistic conception of political legitimacy, in much the same way in which consensus features in more idealistic conceptions of legitimacy (a move that may be attributed to some realist theorists, especially Bernard Williams). My conclusions, however, are largely sceptical: I argue that grounding legitimacy in any kind of normatively salient agreement does require the trappings of idealistic political philosophy, for better or - in my view - worse.
\end{abstract}

Keywords: consensus; compromise; justice; legitimacy; realism; Bernard Williams

\section{Introduction}

The aim of this paper is to investigate whether the notion of compromise can help us overcoming or at least negotiating the frequent tension, in normative political theory, between the desideratum of peaceful coexistence and the desideratum of a morally optimal set of norms and/or institutions. In other words, an analysis of compromise may help us moving beyond the contrast between two widespread contrasting attitudes in contemporary political philosophy: 'fiat iustitia, pereat mundus' on the one side, 'salus populi suprema lex' on the other side. More specifically, as I will outline shortly, compromise may provide the backbone of a conception of legitimacy that mediates between the idealistic and the realistic desiderata of political theory, i.e. between the aspiration to justice and the aspiration to peaceful coexistence. ${ }^{1}$

Of course, compromise is often invoked in political debate, especially in liberaldemocratic contexts. It generally gets a mixed press. Conservatives of Burkean or Oakeshottian inclinations appreciate compromise as one of the ways in which organic and gradual political processes can take place safely far removed from the grand ambitions of political rationalism. More communitarian conservatives, though, are suspicious of compromise in so far as it may be seen as an enabler of the dreaded dilution of a community's

\footnotetext{
${ }^{1}$ Email: enzo.rossi@gmail.com
} 
traditional values and practices. Yet of course there are communitarian but multicultural progressives, who see compromise as an opportunity to foster the coexistence of a rainbow of identities and allegiances. Closing the circle, broadly Enlightenment-driven progressives distrust political compromise as unprincipled and morally suspect. ${ }^{2}$ But if, as political philosophers tend to do, we take a step back from worldly politics, is there still something (theoretically salient) that compromise do for us? This paper considers a sub-set of that question, as it were. It considers whether an account of compromise could help characterising a realistic conception of political legitimacy.

To begin clarifying that question, let me briefly qualify two of its terms. Taking some controversial distinctions for granted (for now), we can say that the notion of legitimacy at stake here is not the empirical one of social science; it is the normative one of political theory. Here legitimacy is not about people's attitudes and beliefs about the exercise of political power, but rather about what reasons there might be to justify the exercise of political power. ${ }^{3}$ Likewise, realism is not the realism of (empirical) international relations theory. It is the realism of those normative political theorists who prefer to adjust their prescriptions to the constraints of real politics, rather than the other way around.

So the question I consider here is whether an account of legitimacy centred around a notion of compromise should appeal to us if we are interested in theories of legitimacy that are designed to accommodate rather than override what one may loosely call 'real politics'. ${ }^{4}$ More specifically, my main focus here is on whether compromise could be for realist accounts of legitimacy what consensus is for idealistic ones.

The paper is structured as follows. I begin by providing some background on the realist trend in recent liberal-democratic theory; then I move on to offer a taxonomy of four types of theories of legitimacy, and explain how one may use the notion of compromise to characterise a realistic voluntaristic theory of legitimacy. In the next section I expand on what exactly compromise might be, and on what problems it might encounter as part of an account of legitimacy. To focus my discussion I concentrate on the realist account of legitimacy recently put forward by Bernard Williams, and show that it may be read as using a notion of compromise as part of its account of legitimacy. The last section summarises the paper's main arguments and conclusions and briefly sketches some further questions that stem from them.

\section{Realism and legitimacy}

In what sense exactly can we talk about a realist streak in contemporary political theory? ${ }^{5}$ Whatever one makes of the familiar narrative according to which Rawls almost singlehandedly revived the discipline in the second half of the twentieth century, it is quite clear that his enormous influence made the dominant trend in the anglosphere an idealistic one, driven by pre-political moral commitments - a result that may surprise us if we look at both the modes of political theorising that preceded Rawls and Rawls' own initial presentation of his view. A distinctive feature of post-Rawlsian idealism is its treatment of political philosophy as a purely normative discipline, whereas most towering figures in the history of political thought just did not distinguish sharply between descriptive and normative theory, implicitly or explicitly acknowledging their interdependence; ${ }^{6}$ Rawls himself initially framed the argument from the original position as based on two descriptive pillars characteristic of the positivistic and behavioural approach that dominated the study of politics in the 1950s and 1960s: rational choice theory and Kohlbergian moral psychology. He later recanted the rational choice claims, and Kohlbergian developmental psychology is now largely discredited; however Rawls' success and (arguably) the debate that ensued after the publication of Nozick's Anarchy, State and Utopia (1974) enabled the normative theory to float free of its claimed descriptive roots, and initiated a decades-long trend of intuitions-driven, idealistic 
theorising. ${ }^{7}$ Yet in recent years a contrarian current of reaction against Rawls' and Dworkin's 'high liberalism' has begun to emerge. Think of the work of theorists like Raymond Geuss (2008), John Gray (2000), John Horton (2010), Glen Newey (2001), and Bernard Williams (2005). ${ }^{8}$ One might even add to that list the recent work on constitutionalism and democracy by Jeremy Waldron (1999) and Richard Bellamy (2006). We would be hard pressed to find anything more than family resemblances among these theorists' positions; nonetheless it is worth sketching the traits that enable us to identify the realist 'family'. 9

Unlike idealism, realism tends to regard politics as a distinctive sphere in need of its own evaluative standards. So realist political philosophy cannot be a branch of applied ethics. Rather, it tries to carve out some space for action-guiding political theory within an analysis of the actual meaning and purpose of politics in a given context. That is to say, it proceeds from an empirically-informed analysis of a society's political culture and, on that basis, tries to produce the most appropriate political prescriptions - which may well not be those that are morally optimal sub specie aeternitatis. In fact, most realists would deny that we can determine what would count as morally optimal without a prior understanding and interpretation of the relevant political context. That move is motivated by two main arguments: on the one hand there is the overhanging suspicion that much purportedly ethicsdriven normative political theory is little more than an expression of ideology. On the other hand, realists observe that, in a sense, the function of politics is precisely to overcome our disagreements about ethics, ${ }^{10}$ so an ethics-driven conception of normative political theory will just not do.

To see where compromise may come into play here, we need to see what a realist approach to legitimacy might look like. ${ }^{11}$ To answer that question I will introduce a distinction between two approaches to legitimacy, voluntarist and substantive, each of which can then be declined in a realist or in a moralist (idealist) way. We thus have four possible ideal types of accounts of legitimacy: moralist and voluntarist, moralist and substantive, realist and voluntarist, realist and substantive.

We have just seen the difference between realism and idealism. Now to complete our conceptual toolbox we need to briefly focus on the voluntarist vs. substantive distinction. Voluntarist accounts of legitimacy maintain that political power is properly exercised in so far as, in some sense, it enjoys the consent of those subjected to it. Typically the consent is hypothetical. This is Rawls' canonical formulation of this idea:

Our exercise of political power is fully proper only when it is exercised in accordance with a constitution the essentials of which all citizens as free and equal may reasonably be expected to endorse in the light of principles and ideals acceptable to their common human reason. (1993, p. 137)

The point is not that the agreement guarantees the presence of certain desirable features of the polity; rather, it is that the very fact that the political framework can be presented as the focus of an agreement makes it legitimate. So this is a somewhat voluntaristic idea, in so far as the source of legitimacy is the (hypothetical) will of the citizenry rather than some aspect of the polity per se. ${ }^{12}$ One may of course question whether any account of hypothetical consent, and particularly public justification-based ones such as Rawls', can have a relevant measure of voluntaristic force. Yet, at least in principle, it does seem plausible to draw a morally significant line between sheer coercion and possible agreement. As Jeremy Waldron puts it, 'Though a social order not legitimated by actual consent may be unfree, that unfreedom can be mitigated by our recognition that it is at least possible to imagine people giving it their consent.' (1987, p. 133) Moreover, it is quite clear from Rawls' discussion of 'stability for the right reasons' that political liberalism is grounded in a consensus of sorts, even though its 
participants are idealised - so the agreement envisaged is not just a way of modelling certain substantive values. This approach has its roots in Locke's political theory, and through Rawls' later work (as the contractualism of $A$ Theory of Justice wasn't really voluntaristic, but rather a way of modelling a conception of fairness) it has become rather dominant in contemporary liberal theory.

On the other hand, substantive accounts of legitimacy ground the exercise of political power in the values, goods and virtues embodied, protected or promoted by a given polity. Agreement here has no direct bearing on legitimacy. It may be considered a useful marker of the presence of this or that substantive good, but it does not carry normative force per se. At least in principle, the citizenry could just be wrong about the merits (or otherwise) of a government's exercise of political power - what confers legitimacy is that government's ability to secure certain goods and values (autonomy, stability, excellence, say), regardless of the citizenry's views on the relative importance of those goods and values. This approach to legitimacy has been dominant throughout the history of (western) political thought, even though it has relatively recently been sidelined by the currently dominant currents of liberalism. Yet, to name just its most prominent liberal supporters, it can be found in David Hume, John Stuart Mill, and Joseph Raz.

It may be useful to illustrate the four kinds of approaches to legitimacy with a few familiar examples. Idealistic voluntarism is found in Locke and in (some readings of) Rawls' political liberalism: in both theories legitimacy is based on a consensus the need for which is justified in terms of pre-political moral commitments - a conception of persons as free and equal for Rawls (1993), an account of natural rights for Locke (1980). Idealistic substantivism is exemplified by Mill (1989) and Raz (1986): both theorists justify political coercion by appealing to substantive pre-political moral commitments (well-being and autonomy, respectively). Realist voluntarism is the sort of approach espoused by a theorist like David Gauthier (1986): political order is grounded in an agreement, but the desirability of such an agreement is not dictated by moral considerations, but rather by a game-theoretic equilibrium. Finally, realist substantivism is best illustrated by Hume (1994): his account of justice and legitimacy does not rely on a consensus (hence his critique of Locke) and it is grounded in a naturalistic description of human society. ${ }^{13}$

We can now turn to the place of compromise. It is probably clear by now why I anticipated that compromise would be an ideal candidate for a central position in a realist voluntarist account of legitimacy. The rough idea is that legitimacy from compromise, like legitimacy from a consensus, is a somewhat voluntaristic project, albeit a more realistic than idealistic one. It is realistic because, as the observation of politics would suggest, the gritty reality of compromise is a more frequent occurrence and easier to obtain than the loftier ideal of a consensus, which seems to rely on an ideal of a citizenry capable of a unity of purposes that has become an unlikely prospect, at least in societies characterized by considerable persistent pluralism. What is more, as Rawls himself recognised, persistent pluralism is a product of the freedoms afforded by the very liberal institutions that idealists tend to favour a problem that has been described as 'the paradox of liberal legitimacy' (Talisse 2005, p. 59). In fact this difficulty in achieving a consensus is one of the main reasons why the turn to realism looks attractive.

And the idea is voluntaristic because, if a polity is legitimate because it is the result of a compromise, then we are saying that it is the fact of agreement that confers legitimacy. If the point is just that if compromise promotes certain substantive values (peace and stability, say), then compromise is not really doing the normatively salient work: a polity that secured those same values by other means would be just as legitimate. Even if compromise were, as a matter of fact, the only way to secure those values the point would still stand (in principle). In 
fact whether compromise brings about desirable values that can produce legitimacy (on a substantivist understanding of legitimacy) is a worthwhile question, but an empirical one. The normative question is what those values are. Here one may object that we could take the very fact of the existence of a compromise as the value that confers legitimacy: compromise as the substantive value that grounds authority. This of course would only work if we accepted something like Daniel Weinstock's (this volume) characterisation of compromise as a principled solution - a move that May (2005) put forward a strong argument against: crudely, there can be no such thing as principled compromise, because the very idea of compromise entails a moral loss, and so should always be considered a regrettable option. In which case it becomes hard to see how a compromise could ground legitimacy and authority (unless one takes a particularly bleak view of the circumstances of politics). But my argument, of course, does not hang on that controversy: either way, what could be valuable about compromise per se if not the fact that it is an agreement, i.e. that it is a way of tracking the presence of a certain relation between fellow citizens? ${ }^{14}$ So that would still be a form of voluntarism (albeit one that is introduced from the back door, as it were).

\section{Legitimacy through compromise?}

So far we have seen where compromise might fit in and play a useful role in a theory of legitimacy. To make that sentence less frustratingly hypothetical, though, we will need to start looking more closely at the very idea of compromise. I will not attempt to offer a strict definition of compromise, as it would in any case be too stipulative to be exhaustive, if only because what we need here is not a general account of what one may mean by 'compromise', but rather a characterisation of the notion of compromise tailored to the specific question under consideration in this paper.

Nonetheless, let us start from one very general and rather platitudinous feature of compromise: compromise affords the avoidance of open conflict. ${ }^{15}$ Quite apart from signalling the deeply political appeal of compromise, in so far as one (and especially a realist) may well take politics to be fundamentally concerned with overcoming open violent conflict, ${ }^{16}$ that leads us towards an observation about what compromise (here) is not: it is not something we individuate on the basis of the process leading up to a result. For instance, sometimes compromise is contrasted to more formal conflict-resolution processes: compromise would be a form of 'informal justice' in the sense that it results in dispute-resolution without the need for third-party adjudication (Luban 1985). However the notion of compromise I have in mind here is not that narrow, and the angle from which I intend to identify it is different. I propose to look not at the process or the procedure that leads to the conflict resolution, but rather at the motivation that parties have to accept a settlement. It is an internal rather than external criterion. The reason for this choice is that if we want the very fact of agreement (rather than what it brings about) to be the source of legitimacy (as required by voluntarism) then we need an account of what the agreement means to its parties (which is unrelated to how the agreement came about, e.g. with or without third-party arbitration, special constraints on the bargaining process, and so on). For the fact that I agreed to something to carry any normative force for me I must have agreed for the right reasons and under the right conditions, whatever those might be.

To clarify, this internal view of compromise is required if compromise is to count as a binding agreement in a voluntaristic account of legitimacy. So the characterisation is stipulative: if there is a sense in which realistic conceptions of legitimacy can rely on a notion of compromise, then this is what they should mean by 'compromise' (that move seems licit insofar as this account of compromise retains a significant amount of proximity to the everyday use of the term). Also note that the sorts of compromises that makes a polity viable 
involve individuals and groups (i.e. they are interpersonal compromises); but on this account that interpersonal compromise supervenes on intrapersonal compromise. For compromise to be possible individuals - groups at best - have to reconcile themselves with the idea that a certain kind of reason is adequate for them to be willing to go along with a certain settlement. How they come to that conclusion (e.g. bargaining and the like) is irrelevant here.

So, what kind of reasons for agreeing (i.e. what kind of motivation) make an agreement a compromise as opposed to a consensus? In a nutshell, a consensus requires some form of endorsement of the terms of the agreement, whereas for a compromise a mere - but genuine willingness to abide by those terms will suffice. Without venturing into the troubled waters of the philosophy of action, on could intuitively cast the distinction as one between obedience and compliance. ${ }^{17}$ Those who participate in a consensus recognise that, even in cases where the settlement is not their preferred outcome, they can (indirectly) endorse it because it is the outcome of a process whose aims and procedures they endorse ('I don't agree with this rate of taxation, but I endorse it as the outcome of a fair process in which we took part as equal and willing partners, etc.'). A paramount example of this is Rawls' overlapping consensus, with its accompanying notions of stability, reasonableness, and civility: the agreement Rawls envisages takes place if and only if the parties endorse it, in the sense that they have higherorder reasons (i.e. the commitment to engage with fellow citizens in certain moralised ways) to abide by its terms even if those terms are not their preferred ones. The parties to a compromise, on the other hand, simply believe that for the time being the settlement is the best achievable approximation of their preferred outcome, and thus that they have reason to uphold it, all-things-considered. It is important to note here that they are still choosing the settlement in a normatively salient sense of the term (i.e. not at gunpoint or under the effect of some drug, say), but they do not have the same level of commitment found in a consensus ('This is the best I can get for now, so I might as well go along with it.', or 'I may be able to secure a better/fairer settlement, but the effort is not worth it.', or simply 'This is not ideal, but it seems acceptable.', and so on). ${ }^{18}$ The point is not that parties to a consensus regard the settlement as ideal whereas parties to a compromise don't. It is possible and perhaps even not infrequent for the parties to a consensus to see their ideal solution being discarded in favour of another one. ${ }^{19}$ The point, though, is that the parties to a consensus will (indirectly) endorse the prevailing solution insofar as they will view it as having the same standing as their preferred one, because they see themselves as sharing the same (mostly moral) goals as the party whose solution prevailed - again, the model is Rawls' overlapping consensus; whereas the parties to a compromise will not. The idea of compromise leaves open how the parties regard other parties' positions. What matters is just their willingness to comply. So also note that on this account of compromise the same settlement (a settlement envisaging the same solution to a dispute, that is) may or may not be a compromise, depending on the parties' motivation for accepting it.

That way of illustrating the consensus-compromise distinction makes it clear why compromise may be seen as a promising cornerstone for realistic voluntaristic theories of legitimacy: something like the notion of compromise can be introduced to retain the intuitive normative force of voluntarism whilst shedding some of the morally controversial and politically impractical moral baggage that comes with the idea of a consensus (as exemplified by Rawls' overlapping consensus). The challenge, then, is to show that compromise can indeed reliably deliver voluntaristic normative force.

Recently Bernard Williams has defended a realist account of political legitimacy which we may read as being centred around a notion of agreement akin to the conception of compromise outlined above. Williams' project is explicitly realist. His account of legitimacy stems from the idea that political theory ought to address specifically political questions, 
rather than act as an idealistic constraint on the exercise of political power, or as an equally idealistic regulatory ideal. The main problem with both of those approaches, which he dubs the 'structural' and the 'enactment' model respectively, is that they both envisage the application of pre-political moral ideals to the practice of politics (2005, pp. 1-2). They aim to shape politics from the outside, as it were. In contrast to that, the key task of political theory should be to focus on inherently political questions - questions that arise given the specific circumstances of politics, which cannot be usefully subsumed under the supposedly more general umbrella of personal morality. In a way that is reminiscent of Machiavelli, the thought is that political morality is not continuous with (or an extension or application of) personal morality. The moral is not prior to the political; rather, political theory should seek to articulate the sort of morality that is appropriate for politics seen as an independent sphere.

The importance of legitimacy is apparent when we consider the sort of questions that, on Williams' view, should be the primary concern of realist political theory: 'I identify the "first" political question in Hobbesian terms as the securing of order, protection, safety, trust, and the conditions of cooperation.' $(2005$, p. 3) For a state to be legitimate, then, simply is to provide a satisfactory answer to that question. But 'satisfactory' does not mean that any arrangement that provides security will ipso facto be legitimate (as in Hobbes 1991). Peace and stability reached through systematic oppression and terror are not really a solution to the initial problem - they do not even qualify as politics. As William Galston puts it in his reading of Williams, 'the use of political power to torture, terrorize or oppress citizens contradicts the point of politics' $(2010$, p. 3). But that is not even to say that anything above that level anything that does qualify as politics - will pass the test of legitimacy. In fact the test of legitimacy is set by what Williams calls the 'basic legitimation demand' (BLD). According to the BLD any solution to the 'first political question' must in some sense be acceptable to those subject to it (2005, pp. 4-6).

Before unpacking that notion of acceptability (as we shall see shortly there is a good reason for its indeterminacy) it is worth noting how it explains in what sense we can think of Williams' theory of legitimacy as relying on a voluntaristic notion of compromise. Williams says that 'the idea of meeting the BLD implies a sense in which the state has to offer a justification of its power to each subject' $(2005, \mathrm{p}$. 4). This is of course a form of hypothetical voluntarism, yet it is one that appeals to reasons that the subjects actually hold, not that they should or could hold. ${ }^{20}$ And this account of acceptability is compatible with our account of compromise because it seems to require less than the moral endorsement envisaged by consensus theorists, yet it does not fall into the trap of an 'everything goes' account of acceptance. It requires willingness to comply, but it does not condone sheer domination. In other words, realist voluntarism embarks on the arduous task of accounting for coercion which idealism unsuccessfully tries to eliminate through the idea of a consensus - without condoning raw domination.

Now let us return to the issue of acceptability and legitimacy. What is acceptable, Williams argues, changes with the times. It is influenced by a complex set of historical factors. This point has some interesting implications if we consider the sort of problems with liberal idealism (or 'high liberalism') that prompted our exploration of realist political theory in the first place. As Williams notes, in modern times the basic legitimation demand by and large requires liberal democracy: 'Now and around here the BLD together with the historical conditions permit only a liberal solution: other forms of answer are unacceptable' (2005, p. 8). In other words, given the conditions of modernity (where, for example, individualism is central), even the seemingly undemanding standard of mere acceptability ends up leading to no less than a liberal solution to the 'first political question'. However, on Williams' realist view, the foundation of liberalism is this process leading to a historically situated 
understanding of what constitutes acceptable treatment of those subject to the exercise of political power, not some externally set moral standard or conception of the person.

One can connect that point with what Rawls says about the idea of an overlapping consensus being implicit in the public culture of liberal democracies (1993, pp. 43-46). If what Rawls says about the background culture of liberal democracies is correct, and that is a fairly big 'if' - but not one that hasn't found some empirical and theoretical support,$-{ }^{21}$ then only a liberal consensus will be acceptable. I am not simply saying that only liberaldemocratic institutions will be acceptable. I am saying that the very idea of acceptance will be the consensus-based one envisaged by Rawls, rather than a weaker, compromise-based one. ${ }^{22}$ In an almost paradoxical twist, the consensus is justified as a compromise. Or, looking at it from the other side (as it were), within (Western) modernity compromise requires a consensus. It just so happens that - if Williams' (and Rawls') empirical account of our background culture is correct - in the context of modernity (in the West) we only compromise if we can find a consensus.

Now the crucial question is this. Does this twist yield a sounder grounding for consensusbased legitimacy and almost a back-door regrounding of idealism, or does it show that realist voluntarism is hopeless (at least in our context) because it ends up with the same problems as its idealist counterpart? I am inclined to defend the latter line. Recall the problems we identified with consensus: if we take pluralism seriously, then we should give up on the search for a consensus. After all this is precisely one of the sorts of considerations that motivated the turn to realism. But now it seems that even if we deploy the weaker notion of a compromise (the BLD idea) and if Williams is right, our culture forces us to demand a consensus. That is to say, even what is just a compromise ends up needing to be a consensus - which we cannot achieve because of pluralism.

Here one might object that, surely, there will be ways to construct a realist voluntarist position other than Williams'. Maybe so; but there is something generalisable in my argument. For instance, Gray (2000) has defended a realist position that seems to me subsumable within Williams': Gray argues that, in our predicament, our best bet to secure peace and stability is usually to converge on a liberal political order. ${ }^{23}$ So the general thought is that voluntarism seems tied to a modern, individualistic cultural background - even if we don't accept Williams' account of legitimacy, it seems hard to reject his matter-of-fact observation of that connection. And we have seen that so long as we are voluntarists and remain within that culture it is impossible to escape the trappings of political idealism, which are problematic given the pluralism generated by that same culture (a Marxist would call this a contradiction of modern liberal ideology). Idealism is flawed, and its flaws spill over into voluntarist realism. Yet, were we to leave this culture, it wouldn't be obvious that voluntarism would carry any salient normative force - after all we can think of many past cultures (including European culture of the past) where that was not the case. Either way, the prospects for voluntaristic accounts of legitimacy are somewhere between hopeless and doubtful.

\section{Concluding observations}

Let us now quickly review the main points we have established. We started by canvassing the contrast between idealism and realism in political philosophy. Some liberal idealists, we saw, ground legitimacy in a moralised consensus; but the conditions of pluralism generated by liberal institutions make it hard for such a consensus to be sustainable. Hence the central question of this paper: if we used the more realistic notion of a compromise instead of that of a consensus, could we still salvage the voluntaristic approach to legitimacy that characterises much contemporary liberal political theory? In other words, if we substitute 'endorsement' with 'willingness to comply', do we get an interesting realist theory of legitimacy that 
overcomes some of the problems of idealistic theories? I argued that that depends on what we take 'willingness to comply' to mean. On some accounts such as Williams', it may end up meaning the same as consensus. In a way that is an interesting development, in so far as it provides consensus theories with a better foundation than the usual, idealistic one they rely on. ${ }^{24}$ On the other hand it may seem that, at least in Williams' version, realism suggests that some of the difficulties (pluralism, seemingly arbitrary exclusion of 'unreasonable' views, etc.) encountered by mainstream idealistic theory are here to stay, at least until the background culture changes. The difference, though, is that they are here to stay not as difficulties within philosophical theories of legitimacy, but rather as difficulties with how our culture reconciles what it understands what is politically acceptable with what it can expect to achieve under circumstances of pluralism. The trouble might well be that the mainstream (liberal) understanding of acceptability (and thus of legitimacy) that is still dominant was tailored for much more homogeneous societies than those eventually produced by the political prescriptions that stem from that same conception of legitimacy. ${ }^{25}$

That realist critique, of course, is a quasi-sociological or historical description of a cultural predicament, rather than an attack on a normative position driven by moral considerations. Does that show that when one adopts a realist perspective normativity almost entirely drops out of the picture? Some idealists may want to put it that way. The matter seems less straightforward to me. Realism relies on empirical considerations such as the ones offered above, but that is not all there is to it. The critique draws on (an interpretation of) some facts to offer some practice-dependent normative considerations. ${ }^{26}$ Perhaps the point is that, on the realist approach as in much of the history of Western political philosophy, there is no such thing as a clear-cut normative-descriptive distinction: fruitful normative political theory has to be in dialogue, as it were, with an empirically-grounded understanding of a society's forms of legitimation. ${ }^{27}$ That is not to say that political philosophy cannot be action-guiding, let alone criticise the status quo. Rather, it cannot do just that, on pain of losing grip on its object.

\section{Acknowledgements}

Versions of this paper were presented at Manchester Metropolitan University and the University of Hamburg - I am grateful to Peter Jones and Fabian Wendt, respectively, for the speaking invitations, and to both audiences for their comments. I should also like to thank Fabian Wendt and an anonymous referee for this journal for their helpful feedback.

\section{Notes}

\section{Notes on contributor}

Enzo Rossi holds a PhD in philosophy from the University of St Andrews (UK) and is Senior Research Fellow in Social Philosophy at the University of Wales, Newport. He has published widely on the theoretical foundations of liberalism and on the problems of legitimacy and realism. At the moment he is completing a book on the liberal political tradition (Bloomsbury, 2013).

\section{References}

Beetham, D., 1991. The legitimation of power. Basingstoke: Palgrave Macmillan. Bellamy, R., 1999. Liberalism and pluralism. London: Routledge. 
Bellamy, R., and Hollis, M., 1999. Consensus, neutrality and compromise. In: R. Bellamy and M. Hollis, eds. Pluralism and liberal neutrality. London: Routledge, 54-78.

Bellamy, R., 2006. Constitutionalism and democracy. Aldershot: Ashgate.

Cohen, G.A., 2005. Facts and principles. Philosophy \& public affairs, 31(3), 211-245.

Galston, W.A., 2010. Realism in political theory. European journal of political theory, 9(4), 385-411.

Gaus, G., 1996. Justificatory liberalism. Oxford: Oxford University Press.

Gaus, G., 2011. The order of public reason. Oxford: Oxford University Press.

Gauthier, D., 1986. Morals by agreement. Oxford: Clarendon Press.

Geuss, R., 2008. Philosophy and real politics. Princeton, NJ: Princeton University Press.

Gray, J., 2000. Two faces of liberalism. Cambridge: Polity Press.

Hallowell, J.H., 1944. Compromise as a political ideal. Ethics, 54(3), 157-173.

Harris, J., 2010. Hume on the moral obligation to justice. Hume studies, 36(1), 25-50.

Hobbes, T., [1651] 1991. Leviathan. Ed. R. Tuck. Cambridge: Cambridge University Press.

Horton, J., 2010. Realism, liberal moralism and a political theory of modus vivendi. European journal of political theory, 9(4), 431-448.

Hume, D., [1748] 1994. Of the original contract. In: D. Hume. Political writings. Eds. S. Warner and D. Livingston. London: Hackett, 164-181.

Klosko, G., 2000. Democratic procedures and liberal consensus. Oxford: Oxford University Press.

Locke, J., [1690] 1980. Second treatise of government. Ed. C.B. Macpherson. Indianapolis: Hackett.

Luban, D., 1985. Bargaining and compromise: recent work on negotiation and informal justice. Philosophy \& public affairs, 14(4), 397-416.

May, S.C., 2005. Principled compromise and the abortion controversy. Philosophy \& public affairs, 33(4), 317-348.

Mill, J.S., [1859] 1989. On liberty. In: J.S. Mill. On liberty and other writings. Ed. S. Collini. Cambridge: Cambridge University Press.

Neal, P., 1993. Vulgar liberalism. Political theory, 21(4), 623-642.

Newey, G., 2001. After politics. London: Palgrave Macmillan.

Nozick, R., 1974. Anarchy, state, and utopia. New York: Basic Books.

Rawls, J., 1993. Political liberalism. New York: Columbia University Press.

Raz, J., 1986. The morality of freedom. Oxford: Clarendon Press.

Rossi, E., 2009. The Exemption That Confirms the Rule: Reflections on Proceduralism and the UK Hybrid Embryos Controversy, Res Publica 15(3), 237-50.

Rossi, E., 2010a. Reality and imagination in political theory and practice: on Raymond Geuss's realism. European journal of political theory, 9(4), 504-512.

Rossi, E., 2010b. Modus vivendi, consensus, and (realist) liberal legitimacy. Public reason, 2(2): 21-39.

Rossi, E., 2012. Justice, legitimacy and (normative) authority for political realists. Critical review of social and international political philosophy, 15(2), 149-164.

Rossi, E., 2013. Legitimacy, democracy and public justification: Rawls' political liberalism versus Gaus' justificatory liberalism, Res Publica. DOI: 10.1007/s11158-013-9223-9

Sangiovanni, A., 2008. Justice and the priority of politics to morality. Journal of political philosophy, 16(2), 137-164.

Sevel, M., 2010. Essays on authority. Thesis (PhD). Department of Philosophy, University of Texas at Austin.

Sleat, M., 2010. Bernard Williams and the possibility of a realist political theory. European journal of political theory, 9(4), 485-503. 
Talisse, R., 2005. Liberalism, pluralism, and political justification. The Harvard review of philosophy, 13(2), 57-72.

Waldron, J., 1987. Theoretical foundations of liberalism. The philosophical quarterly, 37(147), 127-150.

Waldron, J., 1999. The dignity of legislation. Cambridge: Cambridge University Press.

Williams, B., 2005. Realism and moralism in political theory. In: B. Williams. In the beginning was the deed. Ed. G. Hawthorn. Princeton: Princeton University Press, 1-17. 

John Gray (2000) has put forward the most articulate defense of the centrality of peace - and compromise as a means to peace - within the emerging liberal realist tradition. Roughly, the idea is to view liberalism not as legitimated by the substantive values it instantiates, but rather by its ability to arbitrate conflicts and create compromises between divergent substantive values. Peace itself, then, is not a super-value that confers legitimacy on the liberal order, but rather valued insofar as it indicates that a relatively stable compromise has been reached. The argument I offer here, although focused primarily on Bernard Williams' views, may also be read as a critical reaction to this reading of Gray's work. I focus on Williams because I take his view to be the most fully worked out one.

This brief overview contrasts with Richard Bellamy and Martin Hollis's, who see compromise as traditionally conservative territory (1999, p. 55-56). Simon Căbulea May (2005), on the other hand, has a more nuanced take on this subject: compromise has no political colour per se, however it is necessarily unprincipled.

So, of course, the basic distinction still stands even though one may argue the fact that the people believe political power to be legitimate in itself constitutes a reason that justifies the exercise of that power. Relatedly, David Beetham (1991) has convincingly shown that empirical and normative accounts of legitimacy are not easily separable.

See Geuss 2007, Rossi 2010a.

It is also worth noting that most realists refer to the mainstream mode of contemporary political philosophy as 'moralism', whereas here I mostly use the term 'idealism', which seems less contentious.

However an idealistic or moralistic reaction against this approach existed well before Rawls. For an example of work of this kind specifically on compromise see Hallowell 1944. For a recent discussion of how descriptive and normative elements may be integrated see Sangiovanni 2008. The opposite, archidealist view is exemplified by Cohen 2005.

. This trend may owe more to the sociology of the political theory profession than to its intrinsic merits - a point that, of course, betrays my power-centric and realist perspective.

Also note that theorists such as John Dunn (2000) and Patrick Neal (1993) have been arguing along similar lines for much longer.

William Galston (2010) portrayed this emerging family of theories along similar lines.

I use the word 'ethics' to range over the concepts of justice and the good. I have discussed the relationship between justice and teleological values in Rossi 2012.

I have defended the priority of legitimacy over justice (and, relatedly, the superiority of realism over idealism) in Rossi 2012.

Here one may note that Rawls envisages the overlapping consensus as an actual agreement. But then it becomes an agreement between a sub-set of the citizenry of variable and questionable size - the reasonable citizens - picked out by reference to a fixed set of substantive values, namely their commitment to upholding fair terms of cooperation among free and equal members of a liberal democracy. In other words, the agreement is hypothetical relative to the whole of the actual citizenry. In Rossi (forthcoming) I elaborate on this point and, by contrasting Rawls' views with those of Gerald Gaus (1996, 2011), I put forward a modal taxonomy of different kinds of hypothetical agreement (the crucial distinction being the one between possible worlds where the relevant agents can or cannot recognise themselves in their consenting counterparts).

James Harris (2010) has convincingly shown how Hume's account of justice is not tied to the virtue ethics that characterizes his moral philosophy.

In fact this relational aspect is the main distinguishing feature of voluntarism: the sharpest way to bring out the distinction between voluntarism and substantivism is to point out the gap between the thought that political power is grounded insofar as it enables the protection and promotion of certain goods and the thought that the primary purpose of politics is rather to create a framework that enables certain relations between individuals (e.g. reciprocal independence).

Leave aside, for now, the complicated question of what exactly should count as conflict.

16 . Think of the classic contractualist account of politics as the way to leave the state of nature.

17 . For an attempt to work out the action-theoretic basis of this distinction see Sevel 2010, Chs. 2 and 3.

18 . So this account of compromise rules out 'everything goes' theories of modus vivendi, Hobbesian contractarianism like Gauthier's (1986), and the like. I discussed the (lack of) voluntaristic appeal of modus vivendi (as opposed to Rawlsian consensus) in Rossi 2010b.

19 . For instance, Rawls (1993) famously stated that there is a range of conceptions of justice that could be the focus of an overlapping consensus, and that his own preferred conception, justice as fairness, does not have privileged status in that range. 
Galston (2010) and Sleat (2010) also pointed out the search for agreement in Williams' realism.

- George Klosko (2000) conducted empirical research showing something akin to a consensus on the values of constitutional democracy in American public culture. Andrea Sangiovanni (2008) has argued that the most plausible interpretation of Rawls' political liberalism stresses the practice-dependence of legitimate conceptions of justice.

. In Rossi 2010b I have argued that there is no viable middle ground between Rawlsian consensus and Hobbesian 'anything goes' agreement - the point being that the former is too moralistic, and the latter too coercive to be of interest to those wanting to ground legitimacy in some form of voluntariness.

. John Horton (2010) may also be seen as someone who takes such as position; however it seems to me that he rather wishes to defend a voluntaristic account of modus vivendi as a foundation for liberalism (in some context) - a view I have argued against in Rossi $2010 \mathrm{~b}$.

- Though it has been argued that this brings realists too close to idealism (Sleat 2010, Gledhill 2011).

- Rawls famously pointed out how pluralism, reasonable and otherwise, is the inevitable product of life under free institutions.

- On practice-dependence see Sangiovanni 2008 and my own take on that approach in Rossi 2012.

- As noted earlier, David Beetham (1991) has convicingly argued that any good account of legitimacy needs to incorporate both descriptive and normative elements: crudely, moral considerations cannot float free of an actual system of norms and of actual beliefs, pace both Weber's purely descriptive account of legitimation and the fact-independent moralism of much contemporary political philosophy. 